\title{
Pré-moldado (bloco EVAi) para alvenaria intertravada: projeto, produção, desempenho e simulação de uso em habitação social
}

\author{
Precast (EVAi block) block for interlocked masonry: \\ design, production, performance and simulation for use \\ in social housing
}

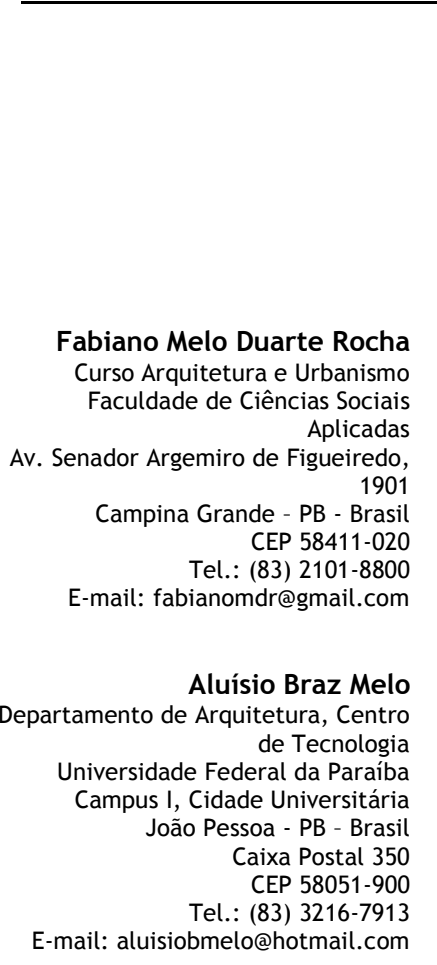

Elisângela Pereira Silva Programa de Pós-Graduação em Arquitetura e Urbanismo, Centro de Tecnologia

Universidade Federal da Paraíba Campus I, Cidade Universitária João Pessoa - PB - Brasil Caixa Postal 350 CEP 58051-900

Tel.: (83) 3216-7913 E-mail:

elisangellapereira@yahoo.com.br

Sandro Marden Torres Departamento de Tecnologia Mecânica, Centro Tecnologia Universidade Federal da Paraíba Campus I, Cidade Universitária João Pessoa - PB - Brasil Caixa Postal 350 CEP 58051-900 Tel.: (83) 3216-7919 E-mail:

sandromardentorres@yahoo.co.uk

Recebido em 06/11/12

Aceito em 26/05/13

\section{Fabiano Melo Duarte Rocha \\ Aluísio Braz Melo \\ Elisângela Pereira Silva \\ Sandro Marden Torres}

\section{Resumo}

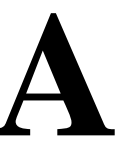

eficácia do projeto para habitação social requer soluções que contemplem os desempenhos técnico e ambiental. Este artigo tem como objetivo abordar os conceitos de coordenação modular e apresentar a proposta do bloco EVAi (Bloco Intertravados contendo Ethylene Vinyl Acetate), levando em consideração avaliações de desempenho mecânico e térmico com base em abordagens conceituais e experimentais. O bloco projetado não possui função estrutural e tem dimensões e geometria compatíveis com alvenaria intertravada. A mistura de concreto leve foi otimizada para a produção dos elementos pré-moldados com incorporação de resíduos da indústria de calçados local. O bloco EVAi traz melhorias ao processo produtivo, tanto pelo desempenho mecânico, leveza e geometria dos componentes como pelas dimensões adequadas. O desempenho térmico das alvenarias com blocos EVAi é melhor em relação a paredes com tijolos cerâmicos convencionais. Alem disto, a geometria intertravada apresenta benefícios para o projeto de habitação social em questão no tocante a ajustes usuais das dimensões dos componentes em alvenarias, reduzindo o desperdício. Comparações entre o sistema construtivo proposto e a tecnologia convencional ressalta a importância do partido arquitetônico como força indutora para o avanço e disseminação de novas tecnologias alternativas sustentáveis.

Palavras-chave:Resíduos EVA. Blocos EVAi. Alvenaria intertravada. Desempenho.

\section{Abstract}

The effectiveness of the social housing design requires solutions concerned with both technical and environmental performances. This article discuss modular coordination and present the proposal for the EVAi (interlocked Ethylene Vinyl Acetate) block, taking into consideration mechanical and thermal performance assessments, based on conceptual and experimental approaches. The proposed block is non-structural, and was designed with dimensions and geometry compatible with interlocked masonry. The concrete mix was optimized for the production of precast elements, incorporating waste from a local shoe industry. The proposed blocks present improvements concerning handling during masonry production, due to the mechanical performance, the lightness of the components and the interlocked geometry with adequate fittings and dimensions. Compared with conventional ceramic brick masonry, the thermal performance of the EVAi block masonry is better. Moreover, the adoption of the interlocked geometry in social housing design resulted in improvements in terms of dimensional adjustments of the components, leading to waste reduction. The comparison between the proposed building system and the traditional technology points out the importance of the architectural design as a driving force for the advancement and dissemination of alternative and sustainable technologies.

Keywords: EVA waste. EVAi blocks. Masonry. Interlocked. Performance. 


\section{Introdução}

Atualmente, sabe-se que o mundo é cada vez mais urbano, sendo a taxa de urbanização no Brasil, desde o ano 2000, superior a $80 \%$ (MARICATO, 2001). Esse fenômeno tem sido acompanhado de um processo de crescente agressão ao meio ambiente, marcado pela exploração descontrolada de recursos naturais e pela alta geração de resíduos. De fato, o funcionamento das cidades contemporâneas está vinculado a fatores como o consumo de energia (incluindo aquela consumida durante a construção e uso das edificações), a geração de resíduos sólidos, a emissão de gases e o consumo de matérias-primas.

O uso de materiais nas edificações urbanas que envolvam menores quantidades de energia em seu processo construtivo, gerem menos poluentes e resíduos ou mesmo os incorporem, e sejam mais facilmente reabsorvidos pela natureza, é uma medida que contribui para o desenvolvimento sustentável. Portanto, na área da arquitetura e da engenharia é importante se pensar em materiais e técnicas de construção que sejam mais amigáveis ao meio ambiente.

Para além dos impactos ambientais referidos, alguns dos graves problemas nas áreas urbanas são exatamente o déficit habitacional e a má qualidade das moradias, sobretudo no segmento populacional de baixa renda, o que vem requerendo especial atenção do poder público e impulsionando o desenvolvimento de pesquisas na área. Cabe destacar que a má qualidade referida tem ocorrido com construção convencional, que emprega materiais industrializados.

Em 2009, no Brasil foi lançado mais um programa ambicioso de financiamento, de iniciativa do Governo Federal, denominado Minha Casa Minha Vida, para a construção de milhões de unidades habitacionais, visando diminuir o déficit que se tem perpetuado há pelo menos cem anos. Esse programa trouxe novamente à tona reflexões sobre a eficácia das políticas habitacionais brasileiras e também sobre o papel da cadeia produtiva da construção civil nesse processo. Mais uma vez, chama-se a atenção para o momento atual, no qual o setor da construção civil está aquecido, com alto volume de construções nas cidades brasileiras. Considerando que é uma atividade que gera muitos resíduos sólidos, é imprescindível se pensar em soluções no sentido de reduzir os impactos ambientais. Nesse sentido, o problema focalizado demanda o desenvolvimento de tecnologia para construção de habitações que possam absorver soluções viáveis com emprego de materiais não convencionais e que incorporem sistemas construtivos que assegurem a qualidade da obra construída.

Outro aspecto importante ao tratar os problemas urbanos é, especificamente, sobre o desenvolvimento do setor industrial, que normalmente é concentrado nas cidades e destacase por impactar o meio ambiente urbano, devido à geração de resíduos, que representam elevados custos para toda a comunidade. Por exemplo, a geração de resíduos no setor calçadista (aparas de solados de sandálias), especialmente de resíduos de etileno acetato de vinila (EVA), tem aumentado bastante, sobretudo no estado da Paraíba, e tem sido proporcional ao crescimento econômico do setor na região. $\mathrm{O}$ volume mensal desses resíduos tem demandado alternativas para um tratamento mais adequado, que não seja simplesmente encaminhá-los para aterros clandestinos ou fornos industriais.

Uma das alternativas encontradas para o aproveitamento de resíduos sólidos, de uma maneira geral, é sua incorporação em materiais destinados à construção civil, por ser este o setor da economia que se destaca pelo grande potencial para absorver vários tipos de resíduos industriais. A grande quantidade de matéria-prima e a diversidade de materiais empregados na produção da construção civil ampliam as opções de uso de resíduos com diferentes funções na edificação.

O presente artigo aborda o resultado de uma ampla pesquisa que tem como pressuposto o incentivo à experimentação de novos materiais com baixo impacto ambiental nos projetos arquitetônicos. O objetivo tem sido oferecer uma alternativa à problemática do destino de resíduos de EVA da indústria de calçados gerados na Paraíba. Especificamente, procura-se investigar o potencial de aproveitamento desses resíduos como agregados leves, na fabricação de blocos cimentícios sem função estrutural (bloco EVA).

Portanto, é nesse contexto que se insere este artigo,que busca uma reflexão propositiva, partindo de um projeto de um novo bloco, aqui denominado de bloco EVAi (bloco EVA intertravado), em que os elementos se encaixam através de intertravamentos, em uma sequência de montagem predefinida. No processo de avaliação, nessa etapa, incluem-se testes de sua produção em escala laboratorial, contemplando análise do desempenho mecânico dos blocos isoladamente e em paredes, submetidas a cargas verticais. Um estudo de caracterização do desempenho térmico do bloco proposto também é apresentado, procurando destacar a possibilidade de agregar 
valor ao produto aplicado nas alvenarias. Finalmente, faz-se a simulação do uso dos blocos propostos em alvenarias num projeto típico de habitação social, semelhante ao adotado no conjunto habitacional Gervásio Maia (Figuras 1 e 2), construído em 2007 pela administração municipal de João Pessoa.

A ideia é demonstrar que o bloco EVAi e o sistema construtivo propostos são compatíveis e adequados para a produção de habitação social, não apenas para o caso de construções em grandes conjuntos habitacionais no espaço urbano. Destaca-se ainda a importância do aproveitamento dos resíduos sólidos (EVA) provenientes de uma atividade industrial local, o que acaba sendo um benefício à própria cidade, onde os resíduos estão sendo gerados em grandes quantidades. $\mathrm{O}$ estudo mostra também que algumas decisões de projeto podem ser combinadas para favorecer a qualidade espacial e ambiental nas habitações, garantir a racionalização do processo de execução (construção seca) e reduzir os resíduos da construção civil (RCC) gerados nos canteiros de obras, entre outros.

\section{Estudos antecedentes com blocos EVA (dimensões convencionais)}

Garlet (1998) é um importante referencial sobre o tema no Brasil, ao tratar do aproveitamento de resíduos de EVA na construção civil. Em sua pesquisa, evidenciou-se a grande potencialidade desse resíduo para uso em diversos componentes e sistemas na construção civil, sem função estrutural. Os baixos resultados de resistência à compressão (0,8 MPa) para os blocos de vedação (14 cm x 19 cm x $39 \mathrm{~cm}$ ) produzidos com os compósitos cimentícios com resíduos de EVA sugeriram inviabilidade do processo. Porém, as características positivas identificadas (bom acabamento das superfícies, uniformidade de medidas, peso reduzido e boa resistência ao impacto) encorajaram a continuidade dos estudos para esse pré-moldado. Para Garlet (1998), a propriedade marcante dos compósitos avaliados foi a baixa rigidez, comportamento atribuído às propriedades do agregado de EVA (baixo módulo de deformação, 1.200 MPa).

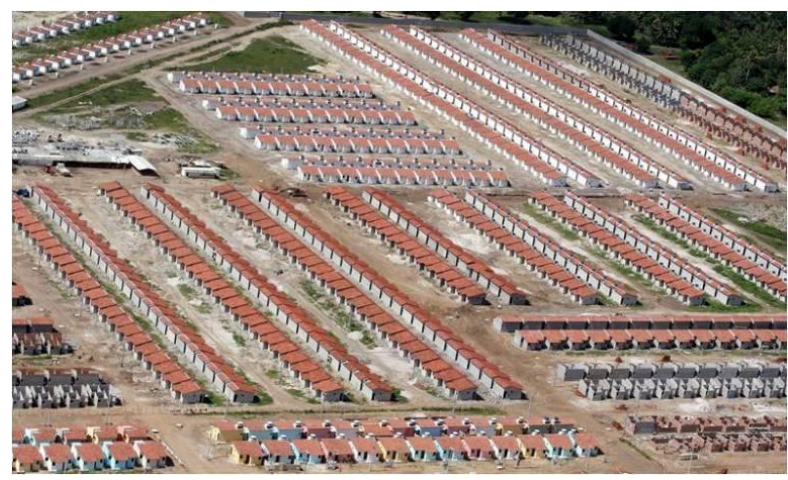

Figura 1 - Vista parcial da distribuição das 1.336 unidades nas quadras do conjunto habitacional Gervásio Maia

Fonte: Suassuna (2013).

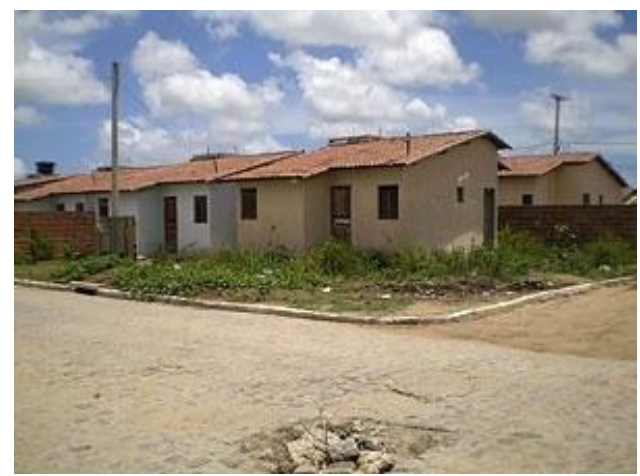

Figura 2 - Implantação das unidades habitacionais nos lotes do conjunto habitacional Gervásio Maia Fonte: Lima (2009). 
Bezerra (2002) desenvolveu uma nova etapa na busca das condições técnicas para utilizar o resíduo EVA como agregado leve na produção de blocos de vedação, com base em compósitos cimentícios. Em seu estudo, destaca-se a dosagem 1:3 (em volume), com a qual obteve resultados de até $2,5 \mathrm{MPa}$, aos 28 dias de idade, para resistência à compressão, e entre $6,2 \%$ e $23,7 \%$ para absorção de água. Em geral, considerando todos os resultados obtidos e as variáveis trabalhadas, quando os valores da resistência à compressão dos blocos EVA $(9 \mathrm{~cm} \times 19 \mathrm{~cm}$ x $39 \mathrm{~cm})$ foram maiores ou iguais a 1,2 $\mathrm{MPa}$, o valor-limite (de acordo com a NBR 6136 (ABNT, 2007)) para a propriedade absorção de água $(\mathrm{Abs}<10 \%)$ sempre foi atendido.

As características favoráveis para o bloco EVA, segundo Bezerra (2002), são os potenciais ganhos na hipótese de sua aplicação: menor peso próprio da alvenaria e maior produtividade em sua execução, pela leveza do pré-moldado, facilidade de corte dos elementos com uma contribuição na menor geração de resíduo de construção e demolição(RCD), etc. Nesse aspecto, John (2000) destaca que, no desenvolvimento de novo produto, deve-se procurar satisfazer as perspectivas dos projetistas e construtores, adequando-se de forma eficaz no processo construtivo e sendo de fácil aplicação. O autor destaca ainda que nos estudos de reciclagem deve-se dar importância ao desenvolvimento de normas técnicas adequadas ao novo produto. Portanto, a possibilidade de definição de novos parâmetros baseando-se em estudos científicos deve ser considerada, admitindo-se, inclusive, uma resistência à compressão mínima mais baixa para o bloco EVA (9 cm x $19 \mathrm{~cm}$ x $39 \mathrm{~cm}$ ), por exemplo, 1,2 MPa, considerando-se que para esse valor o outro parâmetro de norma, absorção de água (Abs $<10 \%)$, normalmente é atendido (BEZERRA, 2002).

Apoiado na avaliação de desempenho mecânico não só de blocos EVA (9 cm x 19 cm x 39 cm) isoladamente, mas também de paredes compostas com eles, Polari Filho (2005) contribuiu na proposição de novo parâmetro de resistência à compressão mínima aceitável para o pré-moldado (1,2 MPa). De fato, seus resultados demonstraram que é possível atingir resistências à compressão de 1,3 MPa para o bloco EVA (9 cm x $19 \mathrm{~cm}$ x 39 $\mathrm{cm}$; com massa $=5,9 \mathrm{~kg}$ ) utilizando dosagem 1:5, com $60 \%$ de EVA, substituindo-se agregados naturais (mesmo valor em MPa obtido com traço $1: 3$, com $80 \%$ de EVA). Nota-se que esse valor (1,3 MPa) é cerca de $60 \%$ maior do que aquele obtido no estudo de Garlet (1998), o que encorajou o prosseguimento das pesquisas, contemplando outras etapas de avaliações dos pré-moldados propostos.

Na sequência dessas avaliações, tem-se o estudo desenvolvido por De Melo e Lima Filho (2009), no qual se verificou o desempenho dos blocos EVA (9 cm x $19 \mathrm{~cm}$ x $39 \mathrm{~cm}$ ) aplicados em alvenarias de uma construção em escala real (protótipo). Nesse protótipo, foram realizados ensaios para verificar o desempenho das paredes diantede cargas de ocupação e impactos, ou seja, foram simuladas situações acidentais e normais de uso, avaliando-se as seguintes ações nas paredes: impactos de corpo mole e de corpo duro, solicitações transmitidas por fechamentos bruscos de porta e cargas provenientes de peças suspensas. A partir dos resultados, os autores destacaram:

(a) bom desempenho das paredes submetidas às cargas provenientes de peças suspensas, com deformações muito inferiores aos valores-limite, com a ausência de arrancamento dos fixadores e quaisquer danos na parede;

(b) resultado positivo pela ausência de danos na interface parede/porta devido às solicitações de fechamentos bruscos por manobras anormais;

(c) bom desempenho das paredes ante os choques decorrentes de impactos de corpo duro de pequena e grande dimensão, considerando-se os registros de $\operatorname{mossas}^{1}$ muitos superficiais no reboco; e

(d) bom desempenho das paredes quando submetidas a impactos (utilização e segurança) de corpo mole, considerando que todos os valores de deformações ficaram muito abaixo dos limites aceitáveis e pela ausência de danos nos componentes acoplados nas paredes (porta e janela).

Para De Melo e Lima Filho (2009), o estudo ofereceu mais uma contribuição no processo evolutivo da pesquisa que visa ao aproveitamento dos resíduos de EVA na produção de blocos sem função estrutural, como uma alternativa válida na execução de alvenarias nos edifícios, indicando positivamente a hipótese de resistência à compressão mínima igual a 1,2 $\mathrm{MPa}$, como parâmetro de norma para o pré-moldado proposto. Mais do que isso, confirmou que a produção dos blocos EVA com uma dosagem 1:5 (em volume), com consumo de cimento Portland igual a 1,7 $\mathrm{kg} / \mathrm{bloco}$, com a proporção ideal entre os agregados (40\% de areia e $60 \%$ de EVA) e com o menor beneficiamento do resíduo para produzir os agregados leves (apenas trituração em moinho de facas para obter agregado com $D_{\text {máx }}=9,5 \mathrm{~mm}$ )

\footnotetext{
${ }^{1}$ Vestígio de pancada ou de pressão.
} 
corresponde ao valor de 1,2 $\mathrm{MPa}$ de resistência à compressão para os componentes.

Todos os estudos antecedentes realizados pelos autores citados consideram o bloco EVA com as dimensões convencionais ( $9 \mathrm{~cm}$ x $19 \mathrm{~cm}$ x $39 \mathrm{~cm}$ ) e para execução de alvenaria, através do processo de assentamento convencional, sem intertravamento entre os componentes. Este trabalho procura dar enfoque ao processo de prémoldagem, tendo em vista a construção seca, na qual os elementos se encaixam por meio de intertravamentos, numa sequência de montagem predefinida. Considerando que se utiliza na moldagem dos novos blocos propostos compósito cimentício leve, devido ao aproveitamento de resíduos de EVA como agregados leves, pensar em componentes com maiores dimensões é interessante visando reduzir o número de blocos/metro quadrado e o consumo da argamassa de assentamento na execução de alvenarias. Porém, é necessário compatibilizar a dimensão e o peso do componente para evitar dificuldades na manipulação dos blocos pelos operários durante a execução da alvenaria, o que certamente comprometeria a produtividade do processo. Uma alternativa é pensar em desenvolver, a partir de estudo de modulação, blocos compatibilizando dimensão (não necessariamente maior), peso e geometria que permitam encaixes horizontais e verticais entre os componentes, de modo a ter-se ainda adequação entre leveza desejável (com maior substituição de agregado natural por EVA) e resistência à compressão igual a 1,2 $\mathrm{MPa}$, conforme é sugerido nos estudos anteriores como aceitável. Essa última alternativa representa o estudo que se apresenta neste artigo.

\section{Bloco para alvenaria intertravada}

As construções em alvenaria assentada a seco são aquelas cujo método de elevação das paredes é executado sem juntas de argamassa na maioria das unidades de alvenaria. Quaisquer tipos de componentes (tijolos ou blocos, maciços ou vazados, fabricados com os mais diversos materiais, tais como concreto, cerâmica, gesso, etc.) que tenham mecanismos de intertravamento entre eles podem ser utilizados. Há na literatura e no setor da construção civil diversos tipos de alvenarias intertravadas, com variações de tipos de materiais, dimensões, geometrias, formas de encaixes (mecanismo de encaixe mecânico ou não mecânico), etc. Essa diversidade indica que a pesquisa desse tipo de sistema construtivo não passa pelo estudo de cada sistema existente, mas pela compreensão dos problemas que esses sistemas se propõem a solucionar e de suas limitações, ou seja, pelo entendimento da lógica com que tais peças foram desenvolvidas.

Os sistemas de alvenarias intertravados oferecem a possibilidade de utilização de mão de obra sem treinamento, ter aumento de produtividade na execução das paredes e ainda diminuir gastos e desperdícios com argamassa de assentamento. Porém, a argamassa utilizada nas alvenarias convencionais assume várias funções importantes, tais como selar as juntas e absorver esforços de flexão, uniformizar a distribuição dos esforços através da parede, propiciar estabilidade durante a elevação e compensar tolerâncias dimensionais do bloco. Vander Werf (1999 apud SALVADOR FILHO, 2007, p.93) ${ }^{2}$ destaca a dificuldade das máquinas convencionais para produzir blocos em série, de modo econômico e com menos que 1,5 $\mathrm{mm}$ de variação na altura. Segundo esse autor, diferenças dessa ordem de grandeza são suficientes para ocasionar desvios no assentamento, com aberturas nas juntas logo após a terceira ou quarta fiada.

Para combater as fragilidades causadas pela ausência da argamassa de assentamento, os sistemas de blocos intertravados geralmente possuem formatos especiais, com encaixes que permitam mais estabilidade do conjunto. Esse tipo de alvenaria pode ser classificado de acordo com a geometria do bloco (maciço, vazado ou misto), mecanismo de encaixe entre os blocos (geométrico ou não geométrico), material utilizado na fabricação do bloco (concreto, concreto leve, cerâmica, gesso, etc.) e aplicação (alvenaria, muro de contenção, etc.). No caso de sistema que adota mecanismos não geométricos de encaixe entre os blocos, as juntas podem receber grauteamento, cola, peças plásticas ou argamassa reforçada (SALVADOR FILHO, 2007).

\section{Estudo do bloco EVA para alvenaria intertravada}

\section{Projeto do novo pré-moldado - Bloco EVAi}

Uma das premissas do projeto do novo prémoldado, aqui denominado bloco EVAi, com dimensões e mecanismos de encaixe, é atender a padrões arquitetônicos míninos dosambientes, levando-se em conta dimensões e alturas usuais nas construções, tais como altura de portas e de janelas, pé-direito, vãos adequados de cômodos e larguras de portas e de janelas. A coordenação

${ }^{2}$ VANDER WERF, P. Mortarless Block Systems. Masonry Construction, p. 20-24, feb. 1999. 
modular entre a definição das dimensões do bloco e tais padrões (Figuras 3 e 4 ) permitiu a redução de cortes desnecessários deles durante a execução da alvenaria.

Assim, o bloco EVAi foi definido a partir de um estudo de repertório de peças e blocos prémoldados consagrados, sendo analisadas várias questões, tais como:

(a) dimensões das peças em relação a seu peso próprio;

(b) tipo e formato dos encaixes;

(c) forma de produção dos blocos (moldagem e desmoldagem);

(d) forma de instalação da peça no canteiro de obra;

(e) relação entre as dimensões, massa e encaixes com o projeto arquitetônico (possibilidades de modulação); e

(f) transporte dos pré-moldados para o canteiro de obra.
Outro fator atrelado às dimensões do bloco de vedação é a relação entre a massa e o tamanho final da peça. Os blocos com dimensões maiores na vertical exigiriam comprimentos maiores pela necessidade mecânica de equilíbrio, e dimensões maiores resultariam numa massa maior para o bloco. Assim, ao se preservarem vazios na parte central do bloco, foi possível reduzir a massa, adequando-o às dimensões propostas para o bloco EVAi (largura $=12,5 \mathrm{~cm}$; comprimento $=25 \mathrm{~cm} \mathrm{e}$ altura $=25 \mathrm{~cm})$.

O encaixe horizontal foi definido em forma de saliência em tronco de pirâmide na parte superior, com dimensões de $3,5 \mathrm{~cm}$ x $3,5 \mathrm{~cm}$, e o correspondente vazio na parte inferior com $4,5 \mathrm{~cm}$ x $4,5 \mathrm{~cm}$. As dimensões adotadas para o encaixe horizontal consideram a necessária folga para facilitar o processo de assentamento das peças na execução da parede. Para o encaixe vertical adotou-se o tipo macho/fêmea, com saliências em baixo e alto relevo correspondentes nas duas laterais do bloco EVAi (Figura 5).

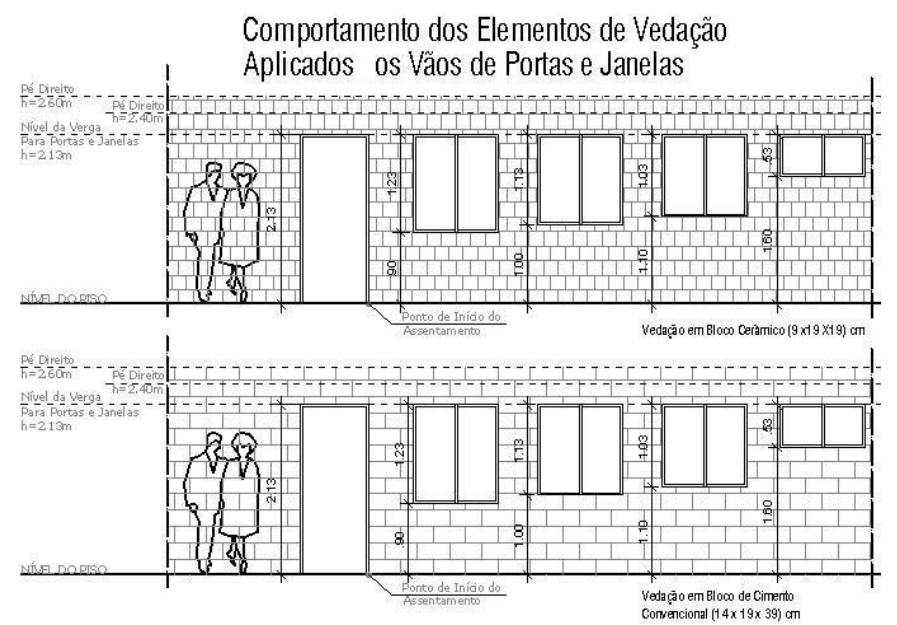

Figura 3 - Comportamento das vedações tradicionais ao fechamento dos vãos Fonte: Rocha (2008).
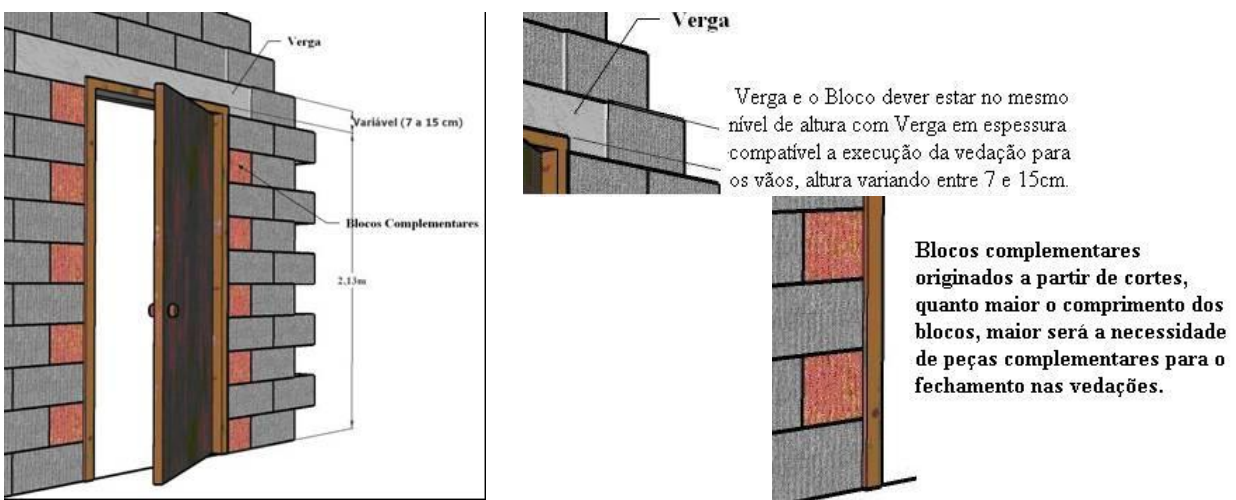

Figura 4 - Relação entre a altura das portas e a altura dos blocos de vedação Fonte: Rocha (2008). 
Para dispensar peças complementares especiais para a construção das alvenarias, a adoção da espessura como metade do comprimento do bloco EVAi permitiu que as amarrações entre painéis acontecessem apenas com a utilização de um "meio bloco" produzido a partir do corte ao meio na peça inteira, corte este facilitado pela característica do concreto EVA (Figura 5). Evidentemente, a posição e as dimensões das saliências que definiram o encaixe horizontal tiveram de ser precisos, para permitir as mudanças de direções e garantir as amarrações entre as fiadas durante a elevação da alvenaria.

De fato, como toda alvenaria racionalizada, alguns cuidados precisam ser adotados na execução dos painéis. Para as amarrações do tipo "T" ou do tipo $90^{\circ}$, por exemplo, os blocos devem respeitar a posição dos encaixes macho/fêmea, obedecendo à modulação múltipla de $12,5 \mathrm{~cm}$ (largura definida para o bloco EVAi), para a formação dos ambientes. Assim, ao iniciar-se o assentamento a $90^{\circ}$, deve-se obedecer à sequência predeterminada, conforme é ilustrado na Figura 6.

Outra condição importante para a definição geométrica do bloco EVAi foi a largura padrão das alvenarias, que geralmente possuem cerca de 15 $\mathrm{cm}$. Assim, considerou-se que esse tipo de bloco (largura de $12,5 \mathrm{~cm}$ ) poderia dispensar a necessidade da camada de chapisco, pois seria possível produzi-lo (o bloco) com a rugosidade característica deste, que certamente garantiria a aderência necessária ao revestimento aplicado posteriormente. Alternativamente, poderia também produzir o bloco EVAi com uma dosagem adequada do compósito cimentício, adotando-se uma granulometria mais miúda para os agregados, de modo a ter um acabamento superficial compatível com a alvenaria aparente, recebendo apenas pintura.

Finalmente, o projeto definido nesta etapa foi resultado da evolução de desenhos até se definirem o comprimento $(25 \mathrm{~cm})$, a altura $(25 \mathrm{~cm})$, a largura $(12,5 \mathrm{~cm})$ e os encaixes nas duas direções, ocorrendo no topo e nas laterais do bloco EVAi.

\section{Produção dos blocos EVAi}

Inicialmente foram realizados os testes de produção do bloco EVAi e, em seguida, realizouse avaliação de desempenho mecânico não só dos blocos isoladamente, mas também das paredes compostas com eles. Posteriormente, foram realizados alguns ensaios para caracterizar o desempenho térmico do componente proposto.
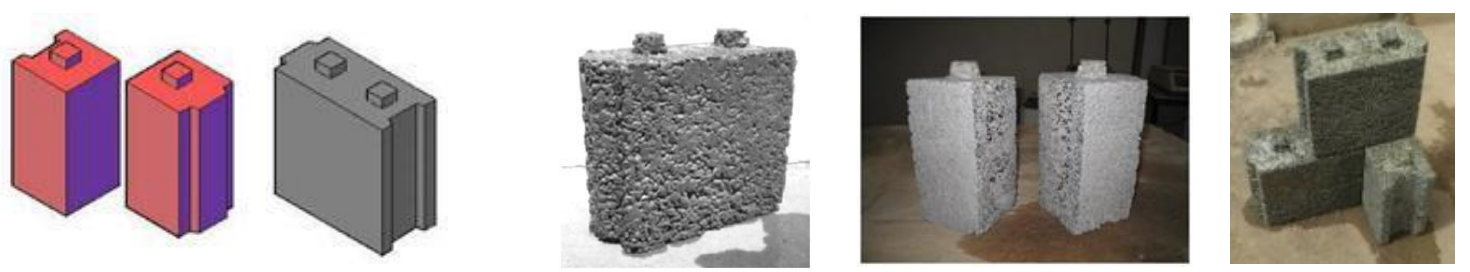

Figura 5 - Bloco EVAi $(12,5 \mathrm{~cm} \times 25 \mathrm{~cm} \times 25 \mathrm{~cm})$ e a possibilidade de corte ao meio, gerando os blocos complementares

Fonte: Rocha (2008).
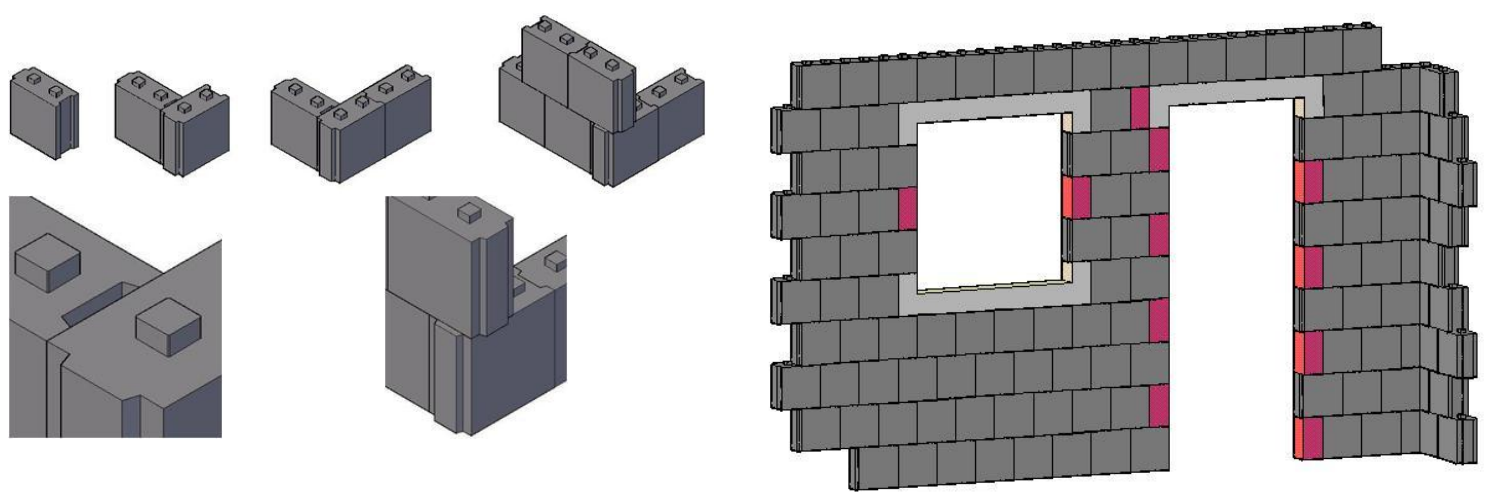

Figura 6 - Sequência indicada para o assentamento dos blocos EVAi $(12,5 \mathrm{~cm} \times 25 \mathrm{~cm} \times 25 \mathrm{~cm})$ Fonte: Rocha (2008). 
Antes de iniciarem-se os testes, os resíduos de EVA foram coletados na região de João Pessoa, $\mathrm{PB}$, diretamente do galpão de uma das indústrias geradoras, já triturado em uma granulometria predefinida $\left(D_{\text {máx }}=9,5 \mathrm{~mm}\right)$. Para testes de produção dos blocos EVAi, eles foram fabricados com dosagem 1:5 (em volume), utilizando-se cimento Portland CP II Z 32, sendo a proporção entre os agregados de $80 \%$ de EVA $\left(D_{\text {máx }}=9,5\right.$ mm e massa unitária $\left.=105 \mathrm{~kg} / \mathrm{m}^{3}\right)$ e de $20 \%$ de areia fina $\left(\mathrm{D}_{\text {máx }}=2,4 \mathrm{~mm}\right)$, adotando-se os controles de produção consolidados em pesquisas anteriores (DE MELO; LIMA FILHO, 2009). A moldagem dos blocos EVAi foi feita em laboratório, utilizando-se máquina vibroprensa semiautomática, sendo todos devidamente curados até completarem 28 dias de idade, por imersão em água saturada com cal. A massa (seca ao ar) dos blocos EVAi assim produzidos, em média, foi igual a $7 \mathrm{~kg}$, sendo a massa específica aparente (seco ao ar) igual a $853,65 \mathrm{~kg} / \mathrm{m}^{3}$. A redução de massa obtida com o uso do concreto leve em relação ao concreto convencional foi de aproximadamente $63 \%$.

\section{Alguns testes de desempenho mecânico do bloco EVAi}

Após o período de cura, os blocos EVAi foram submetidos a ensaios de resistência à compressão. Os ensaios foram realizados com o auxílio de uma máquina universal de ensaios e seguiram todas as recomendações determinadas pelas normas (NBR 12118 (ABNT, 2006) e NBR 7184 (ABNT, 1992)). Como resultado para o Bloco EVAi $(80 \%$ de EVA e $20 \%$ de areia) obteve-se o valor médio igual a 1,2 $\mathrm{MPa}$, exatamente aquele mesmo valor sugerido por De Melo e Lima Filho (2009), o qual havia sido obtido com o mesmo traço (1:5, em volume), porém com menor teor de EVA presente na mistura $(60 \%$ de EVA e $40 \%$ de areia) e com o bloco EVA nas dimensões convencionais (39 $\mathrm{cm} \mathrm{x}$ $19 \mathrm{~cm}$ x $9 \mathrm{~cm})$. Destaca-se que a geometria do bloco EVAi certamente colabora com a possibilidade de compatibilizar leveza (devido à maior presença de EVA) e robustez do componente, mantendo a resistência à compressão dentro do patamar sugerido por De Melo e Lima Filho (2009). Verifica-se, portanto, que com o bloco EVAi consegue-se maior equilíbrio entre uma resistência à compressão desejável, uma leveza interessante para o componente e uma geometria com encaixes e dimensões adequadas para facilitar a manipulação dos elementos durante a execução da alvenaria.

$\mathrm{Na}$ sequência, foram construídas paredes $(1,20 \mathrm{~m}$ de largura x 2,60 m de altura) com os blocos EVAi para avaliar o desempenho quando submetidas à carga vertical. No processo de produção dos blocos EVAi, em escala laboratorial, resultaram imprecisões dimensionais nos componentes moldados, o que gerou a necessidade de uso de argamassa de assentamento, que funcionou como uma cama de 0,5 cm de espessura. Dessa maneira, na execução das paredes foi utilizada uma argamassa de assentamento mista de cimento, cal hidratada e areia, no traço 1:2:4 (em volume), aplicada somente na horizontal, com $0,5 \mathrm{~cm}$ de espessura. De fato, como afirma Vander Werf (1999³ apud SALVADOR FILHO, 2007, p. 93), a argamassa de assentamento tem a função de unir as peças do painel e também de absorver as diferenças dimensionais advindas do processo de fabricação dos blocos. Portanto, o sistema adotado para o mecanismo de encaixe entre os blocos, neste caso, foi o não geométrico.

Acima da última fiada de blocos na execução da parede, para completar sua altura $(2,60 \mathrm{~m})$, confeccionou-se uma cinta de concreto (altura = $12,5 \mathrm{~cm}$ ) com a mesma largura e espessura da parede, para receber a força do pórtico de ensaios e distribuí-la uniformemente sobre a parede. A parede recebeu pintura a cal para facilitar a observação das fissuras durante o ensaio. $\mathrm{Na}$ realização do ensaio de compressão das paredes utilizou-se uma unidade hidráulica elétrica para acionar macacos de duplo efeito (referência I4079, da marca Contenco)(Figura 7), seguindo todas as recomendações da norma NBR 8949 (ABNT, 1985).

A instrumentação das paredes incluiu cinco defletômetros, com precisão de $0,01 \mathrm{~mm}$, sendo quatro deles destinados à medição dos deslocamentos verticais ocasionados pelo encurtamento das paredes, e o outro destinado à medição dos deslocamentos ocasionados pela flambagem (Figura 7c).

Todas as três paredes ensaiadas tiveram bons resultados diante das cargas verticais aplicadas, atingindo-se uma resistência à compressão média de 0,47 $\mathrm{MPa}$, com uma carga de ruptura média igual a $6.653 \mathrm{kgf} / \mathrm{m}$. O valor médio encontrado para eficiência (dada pela relação entre a resistência da parede e a resistência do bloco que a compõe) das paredes foi igual a 0,40, que é o valor mínimo de acordo com Ramalho e Corrêa (2003). Percebeu-se ainda, durante o ensaio, que as paredes mantinham sua capacidade resistente, chegando a suportar quase o dobro da carga imposta desde o momento do surgimento da primeira fissura.

${ }^{3}$ VANDER WERF, P. Mortarless Block Systems. Masonry Construction, p. 20-24, feb. 1999. 


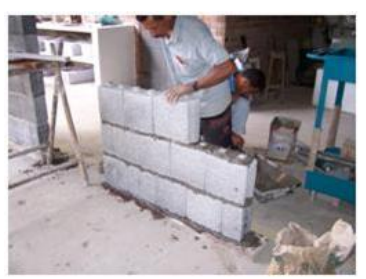

a) execução das fiadas iniciais

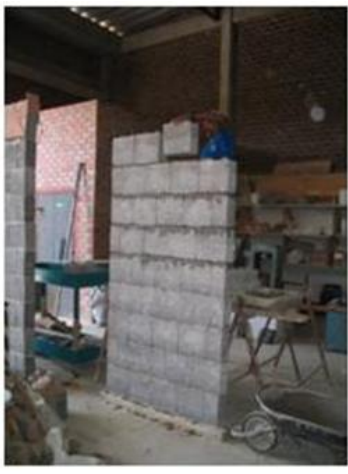

b) destaque para leveza do bloco EVAi

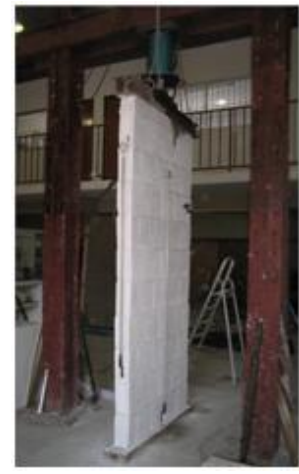

c) instrumentação da parede para medir deformações

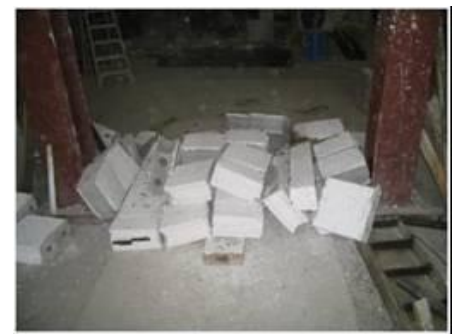

d) blocos inteiros após o colapso da parede

Figura 7 - Execução das paredes e ensaio com cargas verticais

Fonte: Rocha (2008).

Pôde-se perceber também que durante o ensaio de compressão ocorreram maiores encurtamentos das paredes executadas com os blocos EVAi, ou seja, elas se tornaram mais deformáveis comparativamente aos ensaios realizados por Polari Filho (2005).

Então, como já se esperava, tais paredes deformaram-se bastante antes de atingir o colapso do conjunto, e após tal colapso constatou-se que vários blocos romperam-se no encaixe, mas se mantiveram inteiros (Figura 7d). O resultado sugere que uma dosagem com uso de EVA numa granulometria menor (por exemplo, $\mathrm{D}_{\text {máx }}=4,8$ $\mathrm{mm})$ ajudaria no acabamento superficial, no controle dimensional dos componentes moldados e, consequentemente, no melhor ajuste entre os encaixes durante a montagem da parede.

\section{Alguns testes de desempenho térmico do bloco EVAi}

Com o objetivo de caracterizar o desempenho térmico do bloco EVAi proposto, foram realizados experimentos (SILVA; CAHINO; DE MELO, 2012) para medir a variação de temperatura, através de miniparedes sem revestimento, numa análise comparativa do desempenho térmico, considerando vários tipos de blocos EVA e o tijolo cerâmico $(9 \mathrm{~cm}$ x $19 \mathrm{~cm}$ x $19 \mathrm{~cm})$. Também foi realizada análise complementar a partir de cálculos com base em parâmetros térmicos (NBR 15220-2 (ABNT, 2005)).

O ensaio para verificação do comportamento térmico das miniparedes $\left(1 \mathrm{~m}^{2}\right)$ foi realizado no interior de uma câmara térmica. A instrumentação das amostras se fez com dez termopares distribuídos da seguinte forma: cinco deles colocados na face da miniparede exposta ao calor, de modo a ter um termopar central $\left(\mathrm{n}^{\mathrm{o}} 1\right)$ e quatro periféricos; outros cinco termopares foram colocados na face oposta, em posições correspondentes. $\mathrm{O}$ ensaio teve duração de $24 \mathrm{~h}$ com a fonte de calor acionada, sendo esta uma lâmpada de $250 \mathrm{~W}$, posicionada a uma distância de $20 \mathrm{~cm}$ da miniparede. Para a execução da miniparede, utilizando tijolo cerâmico ( 8 furos), os componentes foram adquiridos no mercado local e foram adotados os mesmos procedimentos descritos anteriormente com respeito à instrumentação. A temperatura média global para cada face das miniparedes foi calculada sem considerar os dados registrados nas 4 primeiras horas de ensaio, por ser um período nas quais as temperaturas nos termopares ainda não atingem patamares mais definidos.

Os testes realizados por Silva,Cahino e De Melo (2012) foram com os blocos EVA com dimensões convencionais $(9 \mathrm{~cm}$ x $19 \mathrm{~cm}$ x $29 \mathrm{~cm} \mathrm{e} 14 \mathrm{~cm} \mathrm{x}$ $19 \mathrm{~cm}$ x $29 \mathrm{~cm}$ ), moldados com compósito cimentício e proporção entre os agregados, $60 \%$ de agregado EVA e $40 \%$ de areia, que foram comparados com o bloco EVAi $(12,5 \mathrm{~cm}$ x $25 \mathrm{~cm}$ x $25 \mathrm{~cm}$ ), moldados com proporção entre os agregados, $80 \%$ de EVA e $20 \%$ de areia (neste último caso também se avaliou a composição com $60 \%$ de EVA e $40 \%$ de areia). Inicialmente, ao se compararem os resultados obtidos com as miniparedes construídas - (a) com tijolos cerâmicos e (b) com blocos EVA, ambas com a mesma espessura $(9 \mathrm{~cm}) \quad-, \quad$ verificou-se desempenho semelhante (Tabela 1). Na comparação entre os vários tipos de blocos EVA, destacou-se que tanto a geometria do componente quanto o percentual de EVA incorporado nos prémoldados são aspectos que influenciam em seu desempenho térmico. Como esperado, o maior teor de EVA $(80 \%)$ resultou em aumento do 
desempenho térmico do componente, o que fez o bloco EVAi(único que incorpora $80 \%$ de EVA)se destacar entre os demais comparados, inclusive em relação aos tijolos cerâmicos.

O resultado encontrado por Silva,Cahino e De Melo (2012) está coerente com o que relata Silva (2007) quando afirma que a capacidade de isolamento dos materiais é tanto maior quanto mais poroso forem, sendo o efeito da porosidade eficaz quando os poros são pequenos e fechados, minimizando a transmissão de calor por convecção no interior do material. Certamente, a maior quantidade de EVA (80\%) no bloco EVAi contribui para que ele tenha maior porosidade, o que justifica seu bom desempenho térmico.

Quanto à análise complementar realizada por Silva,Cahino e De Melo (2012), contatou-se que o bloco EVAi (80\% EVA) apresentou a maior resistência térmica $\left(0,3917 \mathrm{~m}^{2} . \mathrm{K} / \mathrm{W}\right)$, ou seja, maior barreira à passagem de calor. Em relação à transmitância térmica (U), o bloco EVAi $(80 \%$ EVA) apresentou o menor valor $\left(2,55 \mathrm{~W} / \mathrm{m}^{2} . \mathrm{K}\right)$, ou seja, o menor fluxo de calor que passaria por ele.

Silva (2007) afirma que a melhor regulação térmica na edificação deve ser atribuída a materiais que possuam, além de uma capacidade térmica elevada, um coeficiente de condutividade térmica reduzido. De acordo com Silva,Cahino e De Melo (2012), essa combinação ocorreu exatamente com o bloco EVAi(80\% EVA), que apresentou a maior capacidade térmica $\left(\mathrm{CT}=202,25 \mathrm{KJ} /\left(\mathrm{m}^{2} . \mathrm{K}\right)\right)$ e o menor valor de condutividade térmica $(0,66$ $\mathrm{W} / \mathrm{mK}$ ) entre os blocos contendo resíduos de EVAensaiados.

Com respeito ao atraso térmico, o bloco EVAi (80\% EVA) apresentou maior valor (4,11 horas) entre os comparados, o que significa um tempo maior que levaria para o ambiente (cuja alvenaria seja executada com o bloco) atingir a temperatura externa (SILVA; CAHINO; DE MELO, 2012).

Considerando os resultados satisfatórios encontrados por Silva,Cahino e De Melo (2012),pode-se destacar que há grande potencial de aproveitamento dos resíduos de EVA como agregados leves na fabricação de blocos de vedação, especialmente no caso do bloco EVAi (80\% EVA), sobretudo pela possibilidade em agregar valor ao componente proposto, considerando a maior capacidade de isolamento térmico e seu bom desempenho térmico.

\section{Simulação de uso do bloco EVAi no projeto de habitação}

O uso dos blocos EVAi nas alvenarias de um projeto de habitação social, através de simulação por desenhos (Figura 8), procurou testar o nível de facilidade ou dificuldade para conciliar as características dimensionais do componente com os requisitos de modulação da alvenaria, buscando avaliar o aspecto de construtibilidade para o caso em estudo. Como se pode observar na Figura 8, o bloco EVAi se mostrou adequado e compatível no processo de execução das alvenarias, com pequenos ajustes nas dimensões dos ambientes do projeto de habitação construído pela administração municipal (Conjunto Habitacional Gervásio Maia Figuras 1 e 2), em 2007, em João Pessoa, PB. A área construída para a unidade habitacional resultante da simulação não difere tanto do caso real construído pela administração municipal, ou seja, nos dois casos as áreas são de $37,6 \mathrm{~m}^{2}$ e de $38,0 \mathrm{~m}^{2}$ respectivamente, o que representa pequena variação. Na simulação foram utilizadas 1.150 unidades de blocos EVAi, respeitando-se o mesmo desenho de planta baixa do projeto de habitação construído pela administração municipal. A imagem na parte inferior da Figura 8 ilustra a possibilidade de manter os blocos EVAi aparentes, inclusive com partes de alvenarias com tonalidade de cores diferentes (ex.: cinza escuro demarcando espaço entre janelas), podendo isso ser utilizado estrategicamente para destacar variações cromáticas diversas entre as unidades habitacionais.

Tabela 1 - Temperaturas médias globais $\left({ }^{\circ} \mathrm{C}\right)$ e suas variações considerando apenas as temperaturas medidas nos termopares centrais, localizados em cada face das miniparedes

\begin{tabular}{c|c|c|l}
\hline $\begin{array}{c}\text { Temperatura da } \\
\text { face exposta } \\
(\mathrm{oC})\end{array}$ & $\begin{array}{c}\text { Temperatura da } \\
\text { face oposta } \\
(\mathrm{oC})\end{array}$ & $\begin{array}{c}\text { Variação de } \\
\text { temperatura entre as } \\
\text { faces }(\mathrm{oC})\end{array}$ & \multicolumn{1}{|c}{ Miniparedes ensaiadas } \\
\hline 39,9 & 28,2 & 11,7 & com bloco EVA 60\% $9 \mathrm{~cm}$ \\
40,9 & 30,2 & 10,7 & com tijolos cerâmicos CER $9 \mathrm{~cm}$ \\
43,9 & 30,1 & 13,8 & com bloco EVA $60 \% 14 \mathrm{~cm}$ \\
42,4 & 28,1 & 14,3 & com bloco EVAi $60 \% 12,5 \mathrm{~cm}$ \\
51,7 & 31,1 & 20,6 & com bloco EVAi $80 \% 12,5 \mathrm{~cm}$ \\
\hline
\end{tabular}

56 Rocha, F. M. D.; Melo, A. B.; Silva, E. P.; Torres, S. M. 


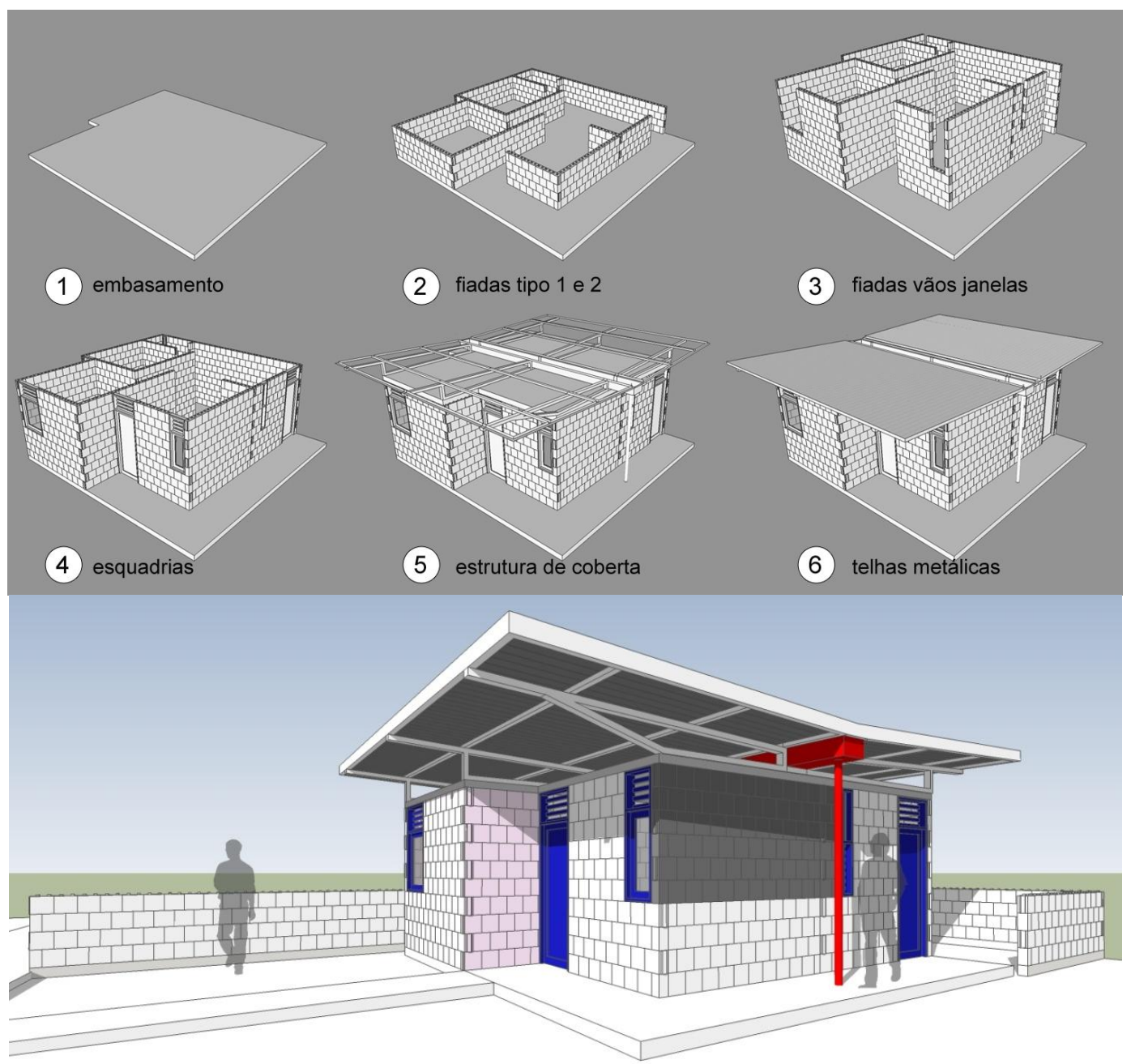

Figura 8 - Simulação do uso do bloco EVAi nas alvenarias de um projeto típico de habitação social Fonte: Rocha (2008).

$\mathrm{Na}$ adequação em relação às esquadrias consideram-se também pequenos ajustes nas dimensões das janelas, apenas invertendo a posição das venezianas, que passaram a ser na parte superior (bandeiras). Então, as alterações na configuração das janelas e portas (também com bandeiras em venezianas) são resultado de posturas projetuais, mas não foram imposição devido ao uso dos blocos EVAi nas alvenarias. Considerando o potencial de desempenho térmico do bloco EVAi em relação a sua capacidade de isolamento térmico, conforme as avaliações demonstradas anteriormente, pode-se esperar que haveria ganhos no desempenho térmico da habitação simulada no projeto, em comparação àquela construída pela administração municipal. Então, neste caso o bloco EVAi colabora para agregar valor ao conforto ambiental da habitação.

Com relação à estrutura de coberta, na simulação decidiu-se pelo uso da estrutura e das telhas metálicas, com maior dimensão para o beiral e uso de laje de forro no limite do perímetro da construção. Essa solução permite a redução de desperdícios provenientes de cortes nos blocos na execução da empena do projeto original. $\mathrm{Na}$ verdade, tal postura projetual tem como justificativa a possibilidade de melhora no desempenho térmico da habitação, tendo em vista se permitir a ventilação do espaço entre a telha e o forro, bem como maior proteção solar das alvenarias e das esquadrias.

\section{Posturas projetuais e impactos ambientais: uma questão de partido}

Ao observar-se o resultado final (Figura 9), é visível o quanto se agrega valor à qualidade do ambiente construído, em função das posturas projetuais incorporadas, que incluem a possibilidade de aplicação dos blocos EVAi nas 
alvenarias. Ademais, deve-se destacar que o uso em larga escala do bloco EVAi nas alvenarias das construções contribuiria para reduzir os impactos ambientais na cidade, considerando os seguintes aspectos:

(a) redução do consumo de recursos naturais para execução da alvenaria, pela substituição de matéria-prima natural por resíduos da indústria de calçados (reciclagem dos resíduos como agregados de EVA);

(b) destinação adequada para os resíduos de EVA com aproveitamento de suas características (baixa massa específica, boas características acústicas e térmicas, dimensionalmente estável, inerte, não suscetível a fungos, etc.) para beneficiar o ambiente construído; e

(c) redução na geração de resíduos durante o processo de produção das alvenarias, em razão de o bloco EVAi ser facilmente cortado na obra, com aproveitamento máximo das partes.

Outro aspecto interessante para a bloco EVAi é a versatilidade de sua aplicação nas alvenarias de diversas tipologias habitacionais, que são desejáveis nas proposições de habitação social. De fato, o bloco EVAi é facilmente aplicável também nas alvenarias sem função estrutural em construções multipavimentos.

\section{Considerações finais}

O presente artigo aborda uma parte de uma ampla pesquisa que tem procurado conciliar as propriedades dos blocos EVA para alvenaria com os critérios e requisitos de desempenho para habitação, que demandam um longo percurso de

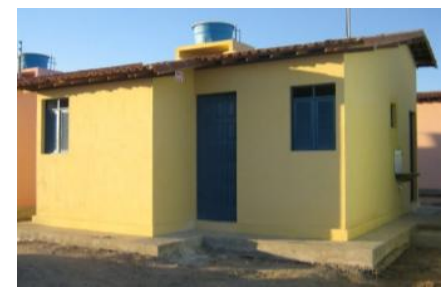

(a) modelo habitacional construído com alvenaria convencional (Conjunto Habitacional Gervásio Maia) avaliações, entre eles aqueles vinculados à segurança, à habitabilidade e à durabilidade. Destaca-se que o objetivo foi demonstrar o potencial que o bloco EVAi, associado ao material de sua composição, pode oferecer à execução de alvenarias nas edificações.

Com base no conhecimento atual sobre o comportamento do material (bloco EVA), no que se refere ao desempenho das alvenarias, especialmente em termos de segurança estrutural, pode-se afirmar que se avançou bastante, como ficou demonstrado pelos estudos apresentados. O bloco EVAi atende ao parâmetro de resistência à compressão mínima de 1,2 MPa, que é o valor que tem sido sugerido.Também há avanços em relação ao desempenho térmico do bloco EVAi, quando se confirmou um desempenho semelhante ao do tijolo cerâmico, componente que é bastante utilizado na região. De fato, é possível estabelecer uma relação de influência entre a presença de resíduos EVA no novo bloco proposto e sua melhoria do desempenho térmico, considerando que ele é um componente cimentício, o que pode significar uma valorização do próprio resíduo e seu processo de reciclagem experimentado.

A partir da análise dos resultados obtidos, pode-se afirmar que com o uso do bloco EVAi é possível conseguir um equilíbrio entre o desempenho mecânico e o térmico, a leveza do componente, a geometria com encaixes e dimensões adequadas, que facilitam sua manipulação durante a execução da alvenaria. Finalmente, a simulação de uso do bloco EVAi num dado projeto de habitação social permite concluir que o pré-moldado proposto tem potencial para uma larga aplicação na construção civil, em alvenarias sem função estrutural.

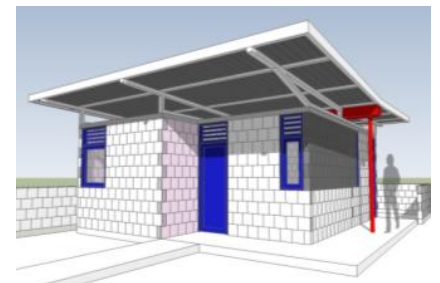

(b) modelo habitacional simulado com alvenaria em blocos EVAi

Figura 9 - Comparação entre o modelo habitacional construído e o simulado

Fonte: Imagem (a) fornecida pela Secretaria Municipal de Habitação Social (SEMHAB) da PMJP (ANO).

Fonte: Imagem (b) Rocha (2008). 
O projeto desse componente está em processo de desenvolvimento, tendo em vista que há uma série de aspectos a serem incorporados nas avaliações de seu desempenho, até atingir a meta do processo de certificação junto à Caixa Econômica Federal (CEF). Na verdade, a cada etapa dos estudos desenvolvidos espera-se contribuir no aumento da credibilidade dos processos de reciclagem de resíduos da indústria de calçados na produção de materiais não convencionais. Tem-se em vista a real possibilidade de redução dos impactos ambientais (uma alternativa ao destino para tais resíduos e uma redução do consumo de recursos naturais), combinada com uma real melhoria na qualidade e no desempenho dos produtos e componentes a serem aplicados em edificações.

\section{Referências}

\section{ASSOCIAÇÃO BRASILEIRA DE NORMAS}

TÉCNICAS. NBR 15220-2: desempenho térmico das edificações: parte 2: método de cálculo da transmitância térmica, da capacidade térmica, do atraso térmico e do fator solar de elementos e componentes construtivos. Rio de Janeiro, 2005.

ASSOCIAÇÃO BRASILEIRA DE NORMAS TÉCNICAS. NBR 6136: blocos vazados de concreto simples para alvenaria sem função estrutural. Rio de Janeiro, 2007.

\section{ASSOCIAÇÃO BRASILEIRA DE NORMAS}

TÉCNICAS. NBR 6136: blocos vazados de concreto simples para alvenaria sem função estrutural. Rio de Janeiro, 2007.

\section{ASSOCIAÇÃO BRASILEIRA DE NORMAS} TÉCNICAS. NBR 8949: paredes de alvenaria estrutural: ensaio à compressão simples: método de ensaio. Rio de Janeiro, 1985.

\section{ASSOCIAÇÃO BRASILEIRA DE NORMAS} TÉCNICAS. NBR 12118: blocos vazados de concreto simples para alvenaria: métodos de ensaio. Rio de Janeiro, 2006.

ASSOCIAÇÃO BRASILEIRA DE NORMAS TÉCNICAS. NBR 7184: blocos vazados de concreto simples para alvenaria: determinação da resistência à compressão. Rio de Janeiro, 1992.

BEZERRA, A. J. V. Utilização do Resíduo da Indústria de Calçados (EVA - Etileno Acetato de Vinila) Como Agregado Leve na Produção de Blocos Vazados de Concreto Para Alvenaria Sem Função Estrutural. 100 f. João Pessoa, 2002. Dissertação (Mestrado em Engenharia Civil) - Escola de Engenharia, Universidade Federal de Pernambuco, João Pessoa, 2002.
DE MELO, A. B.; LIMA FILHO, M. R. F. Avaliação de Desempenho Estrutural de Protótipo Com Paredes Construídas Com Blocos EVA. Ambiente Construído, Porto Alegre, v. 9, n. 4, p. 141-155, out./dez. 2009.

GARLET, G. Aproveitamento de Resíduos de E.V.A. (EthyleneVinylAcetate) Como Agregado Para Concreto Leve na Construção Civil. 146 f. 1998. Dissertação (Mestrado em Engenharia Civil) - Escola de Engenharia, Universidade Federal do Rio Grande do Sul, Porto Alegre, 1998.

JOHN, V. M. Reciclagem de Resíduos na Construção Civil: contribuição para metodologia de pesquisa e desenvolvimento. 113 f. São Paulo, 2000. Tese (Livre Docência) - Escola Politécnica, Universidade de São Paulo, São Paulo, 2000.

MARICATO, E. Brasil, Cidades: alternativas para a crise urbana. Petrópolis, RJ: Vozes, 2001.

POLARI FILHO, R. S. Contribuição ao Processo de Reciclagem dos Resíduos da Indústria de Calçados na Construção Civil: bloco EVA, uma alternativa às alvenarias das construções. $88 \mathrm{f}$. João Pessoa, 2005. Dissertação (Mestrado em Engenharia Civil) - Programa de Pós-Graduação em Engenharia Urbana, Universidade Federal da Paraíba, João Pessoa, 2005.

LIMA, M. A. S. Estudo Comparativo em Habitação de Interesse Social: o caso do conjunto habitacional Gervásio Maia (CHGM) - João Pessoa - PB. Arquitextos, v. 10, set. 2009.

Disponível em:

<www.vitruvius.com.br/arquitextos/arq112/arq112 _02.asp>. Acesso em: 15 jun. 2013.

RAMALHO, M. A.; CORRÊA, M. R. S. Projeto de Edifícios de Alvenaria Estrutural. São Paulo: Pini, 2003.

ROCHA, F. M. D. Aproveitamento de Resíduos Sólidos Industriais em Materiais Alternativos na Perspectiva da Construção Seca: bloco EVA,intertravamento e racionalização das alvenarias. 107 f. João Pessoa, 2008. Dissertação (Mestrado em Engenharia Civil) - Programa de Pós-Graduação em Engenharia Urbana, Universidade Federal da Paraíba, João Pessoa, 2008.

SALVADOR FILHO, J. A. A. Blocos de Concreto Para Alvenaria em Construções Industrializadas. São Carlos, 2007. Tese (Doutorado em Engenharia Civil) - Programa de Pós-Graduação e Área de Concentração em Engenharia de Estruturas, Escola de Engenharia de São Carlos, Universidade de São Paulo, São Carlos, 2007. 
SILVA, C. M. R. L. Análise Técnico/Financeiro de Paredes Externas em Panos Simples. 185 f. Lisboa, 2007. Dissertação (Mestrado em Engenharia Civil) - Instituto Superior Técnico, Universidade Técnica de Lisboa, Lisboa, 2007.

SILVA, E. P.; CAHINO, J. E. M; DE MELO, A. B. Avaliação do Desempenho Térmico de Blocos EVA. In: ENCONTRO NACIONAL DO AMBIENTE CONSTRUÍDO, .14, Juiz de Fora, 2012. Anais... Juiz de Fora: ANTAC, 2012.
SUASSUNA, M. A Versão Projetual da Reflexão Propositiva em Habitação de Interesse Social: o fato do Conjunto Habitacional Gervásio maia (CHGM) - Josão Pessoa - PB. Disponível em: <http://www.marcosuassuna.com/site/estudocomparativo-habitacao-de-interesse-social/> . Acesso em: 15 jun. 2013.

\section{Agradecimentos}

Aos laboratórios onde os ensaios foram realizados, pelo apoio (pessoal e equipamentos) na concretização dos estudos, e à Capes, pelo auxílio financeiro, no âmbito do Prodoc, para a execução desta etapa da pesquisa.

Revista Ambiente Construído

Associação Nacional de Tecnologia do Ambiente Construído

Av. Osvaldo Aranha, $99-3^{\circ}$ andar, Centro

Porto Alegre - RS - Brasil

CEP $90035-190$

Telefone: +55 (51) 3308-4084

Fax: +55 (51) 3308-4054

www.seer.ufrgs.br/ambienteconstruido

E-mail: ambienteconstruido@ufrgs.br

60 Rocha, F. M. D.; Melo, A. B.; Silva, E. P.; Torres, S. M. 